\title{
Reference Time of Concentration Estimation for Ungauged Catchments
}

\author{
John Perdikaris ${ }^{1}$, Bahram Gharabaghi ${ }^{2}$ \& Ramesh Rudra ${ }^{2}$ \\ ${ }^{1}$ Civil Engineering Department, Ryerson University, Toronto, Canada \\ ${ }^{2}$ School of Engineering, University of Guelph, Guelph, Canada \\ Correspondence: Bahram Gharabaghi, School of Engineering, University of Guelph, Guelph, ON., N1G 2W1, \\ Canada. Tel: 1-519-824-4120 Ext: 58451.E-mail: bgharaba@uoguelph.ca
}

\author{
Received: April 4, 2018 \\ Accepted: April 16, 2018 \\ Online Published: May 21, 2018 \\ doi:10.5539/esr.v7n2p58 \\ URL: https://doi.org/10.5539/esr.v7n2p58
}

The research is financed by Natural Science and Engineering Council of Canada (NSERC).

\begin{abstract}
Accurate modelling of flood flow hydrographs in ungauged catchments is a challenging task due to large errors in the estimation of its response time using existing empirical equations. The time of concentration $\left(T_{c}\right)$ is a key catchment response time parameter needed for forecasting of the peak discharge rate and the timing of the flood event. At least eight different definitions have been presented in the literature for the time of concentration. In this study, a new definition of "Reference Tc" is presented along with a practical procedure for its estimation using readily available basin catchment characteristic parameters with the aim of standardizing this key parameter for practitioners. Nine different empirical models were calibrated and tested on nine catchments of the Credit River watershed, Ontario, Canada to determine which method would provide the most accurate prediction of the Reference Tc. The NRCS velocity method (1986) proved once again to be the most reliable and an accurate method. This study shows that the main reason for the higher accuracy of the NRCS velocity method predictions compared to the empirical equations is attributed to the inclusion of the Manning's roughness coefficient.
\end{abstract}

Keywords: hydrograph, time of concentration, catchment, flood, model

\section{Introduction}

A fundamental part of the development of a flood risk maps in ungauged catchments is the use of synthetic unit hydrographs (Atieh et al., 2017). Synthetic unit hydrographs have typically been used to develop stream flow hydrographs for a catchment. Examples of synthetic unit hydrographs include SCS (USDA, 1985), Williams and Haan (1973), or Clark (1945) unit hydrographs. All three of these unit hydrograph methods (as well as most others) require the estimation of the time of concentration $\left(T_{c}\right)$. Fang et al. (2008) showed that $75 \%$ of the total error in estimating the peak flood flows and water levels could be attributed to errors in the estimation of $T_{c}$. Because of the importance of $T_{c}$, different definitions, estimation procedures and empirical equations have been developed over the years to more accurately estimate $T_{c}$.

The time of concentration $\left(T_{c}\right)$ has been defined as (i) the time from the end of rainfall excess to the inflection point on the total storm hydrograph; (ii) the time from the centre of mass of rainfall excess to the centre of mass of direct runoff; (iii) the time from the maximum rainfall intensity to the time of the peak discharge; (iv) the time from the centre of mass of rainfall excess to the time of the peak of direct runoff; (v) the time from the centre of mass of rainfall excess to the time of the peak of total runoff; (vi) the time from the start of the total runoff to the time of the peak discharge of the total runoff; (vii) the time that a drop of rainwater takes to arrive at the basin outlet section starting from the most hydraulically distant point of the basin; and (viii) the time from the end of rainfall excess to the time of the end of direct runoff (Kirpich 1940; Bell and Kar, 1969; NRCS, 1972; McCuen et al., 1984; Garg, 2001; Grimaldi et al., 2013a,b; Seyam and Othman, 2014; Liu et al., 2015; Disley et al., 2015; Ayalew et al., 2015; Petroselli and Grimaldi, 2015; Nardi, 2015; Gazendam et al., 2017). The definition of the time of concentration we will be referring to in this paper as the "Reference Tc" is definition vii, the time that a drop of rainwater takes to arrive at the basin outlet section starting from the most hydraulically distant point of the basin. This definition is reflective of the hydraulic and physical characteristics of the time of concentration and is, 
therefore, more representative of what $T_{c}$ truly is, as opposed to the other definitions, which refer to $T_{c}$ as a characteristic or component of the total hydrograph.

The value of $T_{c}$ can be estimated using hydrometric data. However, measured stream flow or precipitation data for a particular point in a catchment for analysis is rarely available. Therefore, for ungauged catchments, in order to estimate $T_{c}$, equations relating $T_{c}$ to the physical characteristics of the catchment have been used. Since the 1920s many researchers have developed empirical equations for predicting $T_{c}$ for ungauged catchments of varying size and physiography including: Williams (1922), Kirpich (1940), Chow (1962), Kennedy and Watt (1967), Williams (1968), Watt and Chow (1985), NRCS velocity method (1986) and Haktanir and Sezen (1990). With the exception of the NRCS velocity method, these equations were developed using regression analysis, with input parameters as watershed and channel parameters, which include watershed drainage area, channel length, watershed or channel slope, and watershed shape parameters. The equations are listed in Table 1 for System International (SI) units.

Table 1. Empirical equations and models for estimating time of concentration (Tc) in hours (h)

\begin{tabular}{|c|c|c|}
\hline Author & Equation & \\
\hline Williams (1922) & $T_{c}=0.272 \cdot \frac{L_{c} A^{0.4}}{\left(D \cdot S_{c}^{0.2}\right)}$ & \\
\hline Kirpich (1940) & $T_{c}=0.066 \cdot\left(\frac{L_{c}}{\sqrt{S_{c}}}\right)^{0.77}$ & \\
\hline Chow (1962) & $T_{c}=0.000003035 \cdot\left(\frac{L_{c}}{\sqrt{S_{c}}}\right)^{0.64}$ & \\
\hline Kennedy and Watt (1967) & $T_{c}=0.397 \cdot\left(\frac{L_{c}}{\sqrt{S_{c}}}\right)^{0.75} S T^{1.3}$ & \\
\hline Watt and Chow (1985) & $T_{c}=0.0014 \cdot\left(\frac{L_{c}}{\sqrt{S_{c}}}\right)^{0.79}$ & \\
\hline \multirow[b]{2}{*}{ NRCS Velocity Method (1986) } & $T_{c}=T_{\text {sheet }}+T_{\text {shallow }}+T_{\text {channel }} ; \quad T_{\text {sheet }}=\frac{0.0018 L_{\text {sheet }}{ }^{0.6} \cdot n^{0.6}}{i^{0.4} \cdot S_{w}^{0.3}}$ & ; $T_{\text {shallow }}=$ \\
\hline & $\frac{L_{\text {shallow }}}{3.6 C \sqrt{S_{w}}} \quad ; \quad T_{\text {channel }}=\frac{0.44 \cdot L_{c} \cdot n^{0.75}}{i^{0.25} A^{0.125} \cdot S_{c}^{0.375}}$ & \\
\hline Haktanir and Sezen (1990) & $T_{c}=0.734 \cdot L_{c}^{0.841}$ & \\
\hline Arizona DOT (1993) & $T_{c}=0.00031 \cdot A^{0.1} L^{0.25} L_{c a}^{0.25} S_{w}^{-0.2}$ & \\
\hline Sharifi and Razaz (2014) & $T_{c}=0.39 \sqrt{A}+D D^{2}$ & \\
\hline
\end{tabular}

Note: For SI units, main channel length Lc, basin equivalent diameter D, length of sheet flow Lsheet, length of shallow concentrated flow Lshallow, length of the basin along the main channel from the hydraulically most distant point to the outlet $\mathrm{L}$, and length measured from the concentration point along $\mathrm{L}$ to a point on $\mathrm{L}$ that is perpendicular to the basin centroid Lca, and drainage density DD are in $\mathrm{km}$, area A is in $\mathrm{km} 2$, and Sc main channel slope and Sw basin slope are in $\mathrm{m} / \mathrm{m}$ and $\mathrm{C}$ is equal to 4.918 for unpaved areas and 6.196 for paved areas.

Williams (1922) developed an equation to estimate $T_{c}$ (Table 1) based on a study on flood discharge in India. The parameters within Williams' equation include the drainage area of the basin $(A)$, the equivalent diameter $(D)$ of a circular basin with the same drainage area, the main channel length $\left(L_{c}\right)$ and the main channel slope $\left(S_{c}\right)$. Williams' equation is typically applied to watersheds with drainage areas less than $129.5 \mathrm{~km}^{2}$ (Fang et al., 2008). 
Kirpich (1940) developed an equation to estimate $T_{c}(\mathrm{~h})$ for small mountainous watersheds in Tennessee. The parameters within Kirpich's equation include the main channel length $\left(L_{c}\right)$ and the main channel slope $\left(S_{c}\right)$. The watersheds used in Kirpich's study ranged in size from 0.004 to $0.45 \mathrm{~km}^{2}$, with slopes from 3-12\%. McCuen et al. (1984) commented on how Kirpich's equation had the smallest amount of bias for watersheds with significant channel flow. In addition, Fang et al., 2008 showed Kirpich's equation to provide reliable estimates of $T_{c}$.

Chow (1962) developed an equation to estimate $T_{c}(\mathrm{~h})$ based on data from 20 basins in Illinois, Ohio, Missouri, Wisconsin, Indiana, Iowa and Nebraska with drainage areas ranging from $0.012-18.5 \mathrm{~km}^{2}$. The parameters within Chow's equation include the main channel length $\left(L_{c}\right)$ and the main channel slope $\left(S_{c}\right)$. Chow's equation is similar in form to Kirpich's equation. However, Chow's equation has not been utilized as widely as Kirpich's equation, even though it is based on data from basins with a wider range of drainage areas and in different regions.

Kennedy and Watt (1967) developed a prediction equation for $T_{c}$ (h) using data from 12 gauged basins in Southern Ontario Canada. Their equation is relevant to this study because it is based on a sample of drainage areas that are much larger (58.8-202 $\left.\mathrm{km}^{2}\right)$ than those of the previous studies described above and are located in Canada. The parameters included in this equation are the main channel length $\left(L_{c}\right)$, main channel slope $\left(S_{c}\right)$ and the storage factor $(S T)$. The $S T$ parameter is defined as $\left[1+A_{s} / A\right]$, where $A_{s}$ is the surface area of wetlands, lakes, and ponds on the upper two thirds of the drainage basin and $A$ is the drainage area of the basin. With the exception of the storage parameter ST, the equation is similar in form to Kirpich's and Chow's equation.

Watt and Chow (1985) developed an equation to estimate $T_{c}$ that was based on basin data derived from previous studies including Kirpich (1940), Chow (1962), Kennedy and Watt (1967) and basins from Quebec. The collected data cover a wide range of basin size, from 0.5 ha to $5840 \mathrm{~km}^{2}$, and the basins are located across North America from the mid-west United States to Quebec in Canada. The channel length varies from $100 \mathrm{~m}$ to $200 \mathrm{~km}^{2}$ and the channel slope from 0.001 to $0.09 \mathrm{~m} / \mathrm{m}$. The equation is similar in form to the previous 3 equations.

Time of concentration estimated using the NRCS velocity method (1986) is based on the sum of the travel time $\left(T_{t}\right)$ values for the various consecutive flow segments including sheet flow $\left(T_{\text {sheet }}\right)$, shallow concentrated flow $\left(T_{\text {shallow }}\right)$ and channel flow $\left(T_{\text {channel }}\right)$. The travel time is the ratio of the flow length to flow velocity $\left(T_{t}=L / 3600 \mathrm{~V}\right)$ where $L$ is the flow length $(\mathrm{m}), V$ is the velocity $(\mathrm{m} / \mathrm{s})$, and 3600 is a conversion factor from seconds to hours. The velocities $(V)$ for the sheet flow and channel flow were derived using Manning's equation. The procedure for deriving the sheet flow velocity and channel flow velocity is illustrated in TR-406 Soil Water Assessment Tool Theoretical Documentation Version 2009 by Neitsch et al., 2011. The same procedure was applied here to derive the equations for sheet flow and channel flow travel times. In the equations for computing the travel time for sheet flow $\left(T_{\text {sheet }}\right)$ and channel flow $\left(T_{\text {channel }}\right)$ the parameter $i$ refers to the 2 years, 24-hour rainfall duration which is selected from the intensity duration frequency (IDF) curve for the region. Typically after $100 \mathrm{ft} .(\sim 30 \mathrm{~m})$, sheet flow usually becomes a shallow concentrated flow. The average velocity for shallow concentrated flow can be determined using the equations stipulated within NRCS Urban Hydrology for Small Watersheds v 2.1, 1986 for both unpaved $\left(V=4.918 \sqrt{ } S_{w}\right)$ and paved $\left(V=6.196 \sqrt{ } S_{w}\right)$ areas. Where $V$ is the velocity in $(\mathrm{m} / \mathrm{s})$, and $S_{w}$ is the average slope of the basin $(\mathrm{m} / \mathrm{m})$.

Haktanir and Sezen (1990) developed two-parameter gamma and three-parameter beta distributions as synthetic unit hydrographs for ten watersheds in Anatolia, Turkey. Regression analyses for peak discharge and NRCS lag time of ten observed unit hydrographs were performed to develop the regression equation. $T_{c}$ is computed from basin lag time based on the NRCS relationship $T_{L}=0.6 T_{c}$ (NRCS 1972, 1986). The Haktanir and Sezen method only include the main channel length $\left(L_{c}\right)$ as an input parameter. Fang et al., 2008 showed the Haktanir and Sezen equation to provide reliable estimates of $T_{c}$.

The Arizona DOT method (1993) is based on a modified version of the FAA method (1970). Where $L$ is the length of the basin along the main channel from the hydraulically most distant point to the outlet (longest flow path); $L_{c a}$ is the length measured from the concentration point along $L$ to a point on $L$ that is perpendicular to the centroid of the basin (longest flow path to the centroid of the basin); and $S_{w}$ is the average slope of the basin. This equation is typically applied to agricultural watersheds.

Sharifi and Razaz (2014) used GIS and genetic programming to derive a series of equations for estimating the $T_{c}$. The equations were derived using data from 72 basins and sub-basins of different sizes and characteristics in the Khorasan Razavi province of Iran. The drainage areas for these basins ranged from $18.8-376.7 \mathrm{~km}^{2}$, and their flow lengths ranged from 11.6-35.3 km. A comparison among the highest ranked expressions revealed that the equation listed in Table 1 was the simplest and most suitable equation for estimating $T_{c}$ in the study region. The inputs to this equation are the drainage area of the basin $(A)$ and the drainage density of the basin $(D D=$ channel length/drainage area). 
However, the most popular approach for determining $T_{c}$ is the NRCS velocity method. Past experience and previous studies have shown that the NRCS velocity method is considered to be the most accurate method for estimating $T_{c}$ for both rural and urban catchments (McCuen et al., 1984; Fang et al., 2008; Sharifi and Hosseini, 2011; Perdikaris et al., $2011 \&$ 2018). This is primarily due to the fact that the velocity method is based on hydraulic principles, and as a result is more reliable than purely empirical equations.

Key variables among the equations listed in Table 1 are the main channel length $\left(L_{c}\right)$, the main channel slope $\left(S_{c}\right)$ and the drainage area $(A)$. Other variables include the longest flow path $(L)$, longest flow path to the centroid of the basin $\left(L_{c a}\right)$, average basin slope $\left(S_{w}\right)$, drainage density $(D D)$ and Manning's "n." Manning's roughness coefficient $(n)$ is used in the NRCS velocity method because Manning's equation is used to estimate runoff velocity. All of the above variables can be easily measured using manual methods from hard copy paper topographic maps or use automated methods from GIS. Although, these equations include the same key variables, their predictions of $T_{c}$ vary considerably. Fang et al. 2008 showed that averages in relative differences in $T_{c}$ estimated using different empirical equations with the same set of basin parameters range from -38 to $207 \%$. In addition, all of the equations have shortcomings with respect to the inadequate representation of physical data and the presence of large prediction errors. Fang et al., 2008 reported that differences in estimating $T_{c}$, based on the method used to collect basin parameters were minor sources of error, in relation to other uncertainties inherent in time parameter estimation. Compared with actual stream measurements, all of the equations yielded significant errors in the prediction of $T_{c}$ (Kibler and Aron, 1983; Goitom, 1989; McCuen et al, 1984; Sharifi and Husseini, 2011; Gericke and Smithers, 2013; Perdikaris, 2013; Grimaldi et al., 2013a, b; Seyam and Othman, 2014; Ayalew et al., 2015; Petroselli and Grimaldi, 2015; Nardi, 2015). Therefore, a more reliable approach is required for predicting $T_{c}$.

\subsection{Objectives}

The main objective of this study is to present "Reference $T_{\mathrm{c}}$ " as a new definition along with a practical procedure for its estimation using readily available basin catchment characteristic parameters to standardize this key parameter for practitioners. In this study "Reference $T_{c}$ " refers to the time that a drop of rainwater takes to arrive at the basin outlet section starting from the most hydraulically distant point of the basin. The path the water travels along is referred to as the longest flow path, and it is typically subdivided into 3 separate flow segments sheet flow, shallow concentrated flow, and channel flow. Nine different empirical models were tested on nine sub-basins of the Credit River in Southern Ontario, Canada to determine which method would provide the most accurate estimation of the reference

\section{Method}

In this section, the methodology for obtaining the reference time of concentration values using a combination of hydraulic information and Geographic information System (GIS) data is presented. This is followed by a discussion on the methodology used to evaluate and compare the different methods. In total, 9 sub-basins of the Credit River were used to undertake the comparative analysis of the equations.

\subsection{Reference Time of Concentration}

The Ontario Flow Assessment Technique (OFAT) data model version III (MNR 2001; Chang et al., 2002) was used to calculate the reference time of concentration values for the Credit River watershed. Using GIS tools, the OFAT data model has the ability to process spatial data and automatically calculate basin parameters such as main channel length and slope, improving the speed and accuracy of the travel times computed (Green and Nelson, 2002; Sharifi and Hosseini, 2011). To compute the reference $T_{c}$ values for the sub-basins of the Credit River, the following steps were performed:

1. The flow path network is derived by the OFAT model by following the path of steepest descent across the basin. Elevation data is available in the OFAT data model as a 10-m digital elevation model (DEM).

2. Water Survey of Canada (WSC) stream flow gauging stations were selected as outlet points along the flow network, the location of the WSC stream flow gauging stations and their associated flow paths are illustrated in Figure 1. 


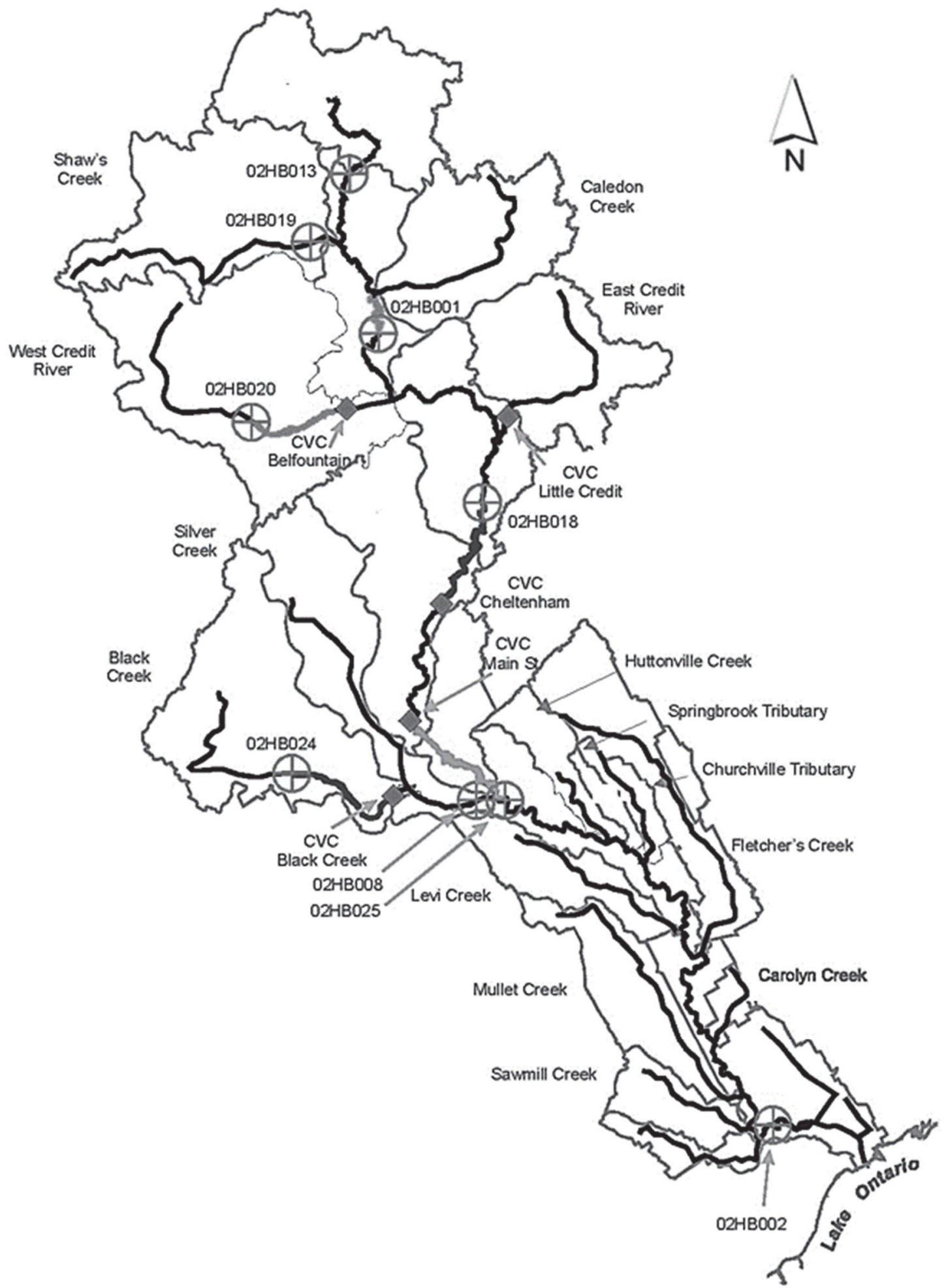

Figure 1. Flow paths, subbasins, tributaries and gauging stations along the Credit River Basin (base map supplied by the CVC)

3. The longest flow path $(L)$, the main channel length $\left(L_{c}\right)$, average basin slope $\left(S_{w}\right)$, average main channel slope $\left(S_{c}\right)$, drainage area $(A)$, drainage density $(D D)$ were calculated by the OFAT model for each outlet point (Table 2). In addition, the percentage of upstream wetlands, ponds, and lakes $\left(A_{s} / A * 100\right)$ was calculated by the OFAT model for each outlet point. This value was then used to calculate the storage (ST) value for each outlet point $S T=\left[1+20^{*}\left(A_{s} / A\right)\right]$ (Table 2). Average Manning's "n" values were calculated 
for each outlet point using Manning's formula and the measured velocity data, water levels, wetted top widths, wetted cross-sectional areas, and wetted cross-sectional perimeters for each WSC gauging station.

Table 2. Physical parameters for the basins along the Credit River watershed

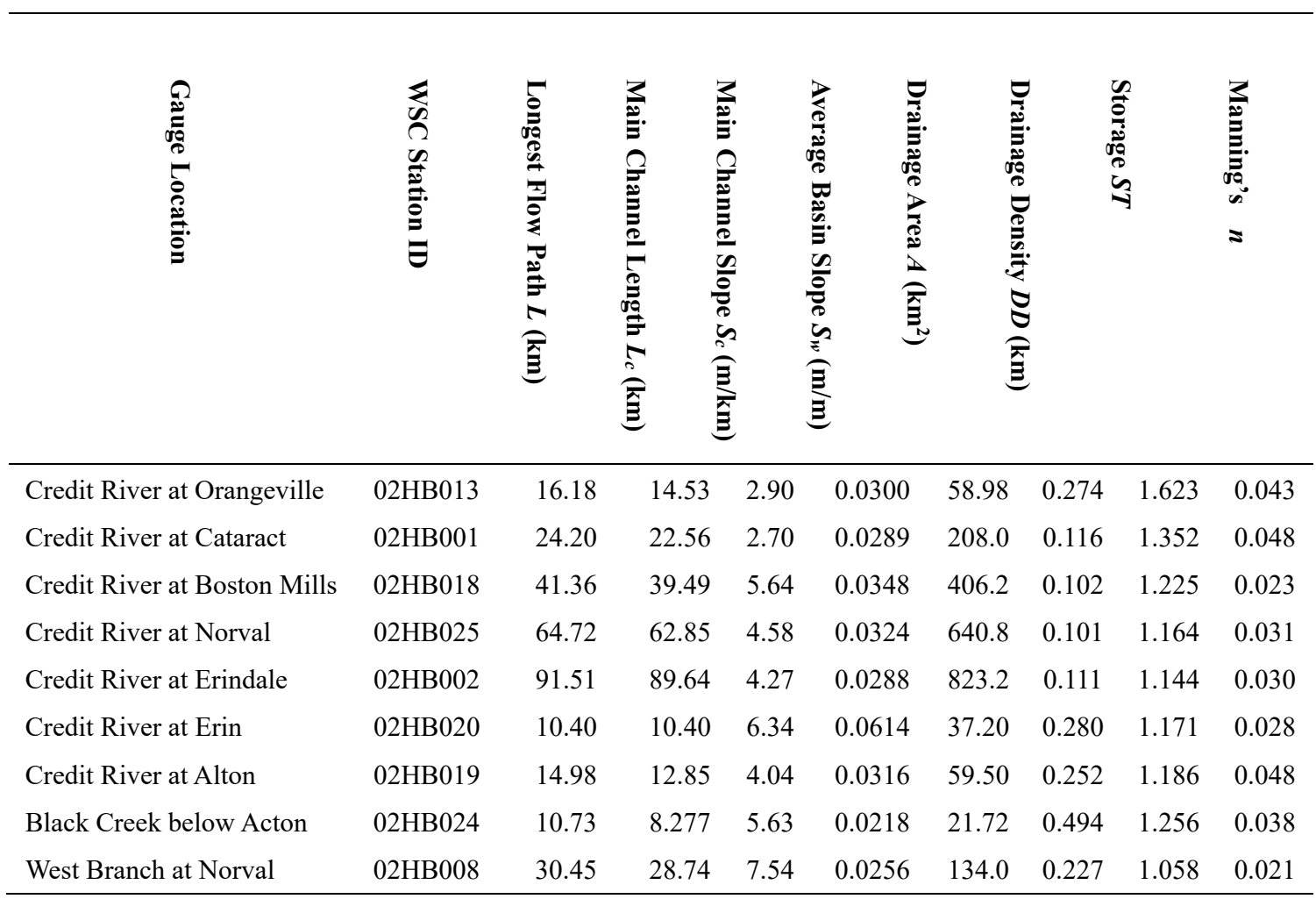

4. The longest flow path was divided into two flow segments shallow concentrated flow and channel flow.

5. The velocity for shallow concentrated flow is a function of the slope and the channel conveyance. The velocity for shallow concentrated flow is equal to $6.196 * S^{0.5} \mathrm{~m} / \mathrm{s}$ for paved areas and $4.918 * S^{0.5} \mathrm{~m} / \mathrm{s}$ for unpaved areas (NRCS, 1986). The travel time for the shallow concentrated flow was determined by dividing the shallow concentrated flow length by the shallow concentrated flow velocity. The shallow concentrated flow length was calculated by subtracting the $L_{c}$ from $L$.

6. The bank full stream flow rate was determined by calculating the 2-year return period flow rate at each stream flow gauge and dividing it by 1.16 . The value of 1.16 was determined by analyzing stream flow rates and bank full discharge rates recorded at stream flow gauges across Ontario. The value 1.16 is the median value for the ratio between the 2-year peak flow rate and the bankfull discharge (Figure 2). The values were abstracted from the "Database of Morphologic Characteristics of Watercourses in Southern Ontario," (Annable, 1994). Discharge - velocity curves for the WSC gauge stations were used to determine the bank full flow velocity. 


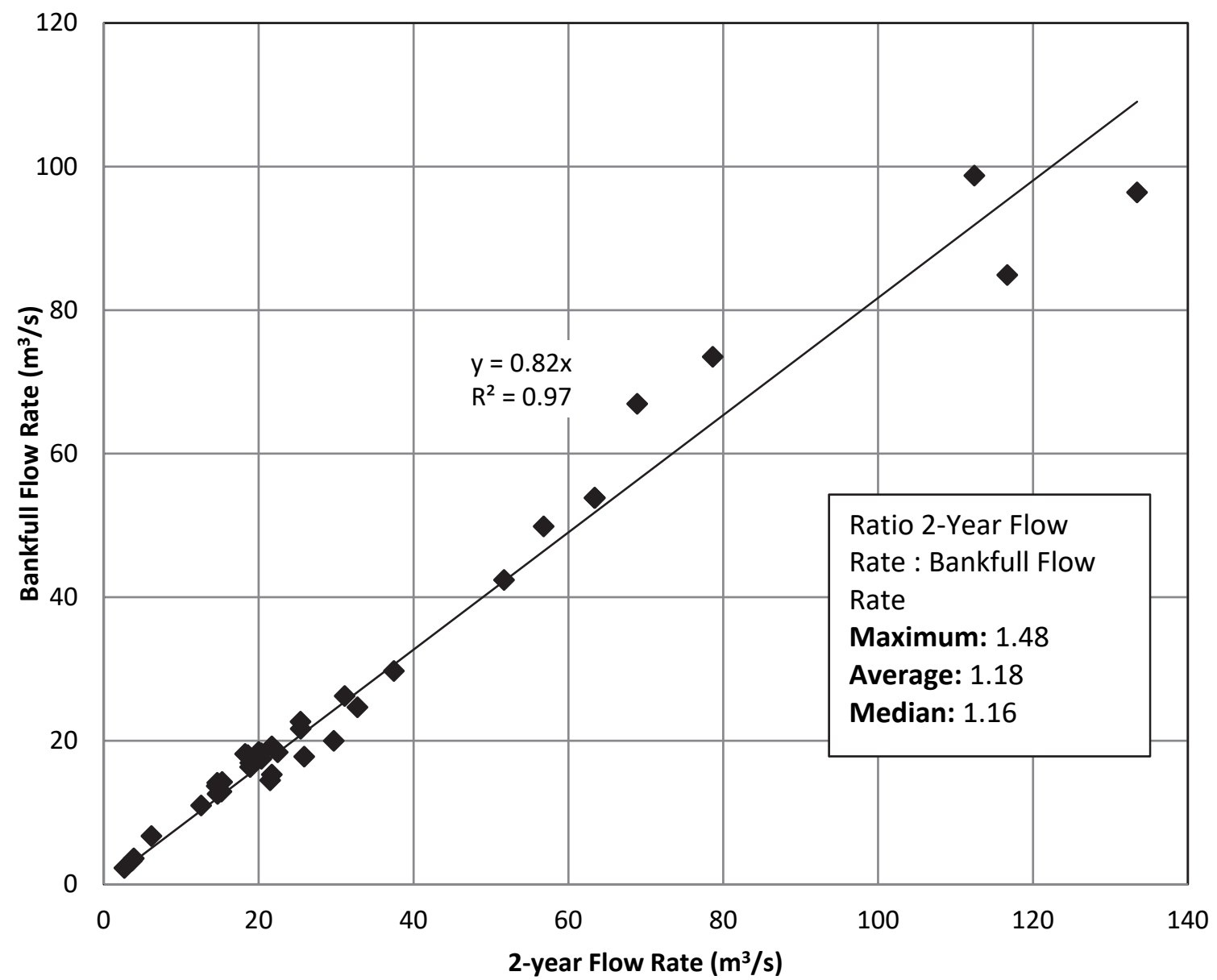

Figure 2. The linear correlation between the 2-yr flow rate and the bankfull flow rate for WSC stations across Ontario

7. The velocity and travel time along the longest flow path was calculated using the method of reciprocal slopes. A profile plot of the longest flow path was abstracted using the GIS tools and imported into an Excel spreadsheet. A reach is represented by the distance between two elevation points along the flow path's profile. Assuming that the conveyance along the flow path is constant, the stream flow velocity for each reach along the flow path was determined by multiplying the stream flow velocity at the WSC gauge with the ratio of the square root of the bed slope for each reach divided by the bed slope at the WSC gauge. Travel time through a reach was calculated by dividing the reach distance with the reach velocity.

8. The travel times along the flow paths were then summed to determine the reference time of concentration $\left(T_{c}\right)$ values at the outlet point for each catchment along the Credit River. If observed flow data is unavailable, Manning's equation can be used to calculate the flow velocity at the outlet point; step 7 could then be used to calculate the flow velocities and travel time for each sub-reach along the flow path.

\subsection{Performance Evaluation of the Models}

In order to evaluate the performance of the different methods, each approach was applied to a series of catchments along the Credit River watershed. The reference values for $T_{c}$ along with the physical parameters of the catchments used in their evaluation are listed in Table 2. For evaluation purposes, ASCE (1993) recommends that a combination of graphical plots and statistical goodness-of-fit measures be used to assess the accuracy of a model or equation. The statistical measures selected to assess the equations were the mean absolute error $(M A E)$, mean absolute percentage of errors (MAPE), the sum of errors (SE), percent bias (PBIAS), root mean square error (RMSE) and the coefficient of determination $\left(R^{2}\right)$. These statistical measures in combination with scatter plots and residual plots of the reference and estimated $T_{c}$ values were used to measure and compare the bias and accuracy of the 
equations for the Credit River watershed. For a review of the different evaluation methods and statistical goodnessof-fit measures the reader is referred to Gupta et al., (1999), Singh et al., (2004) and Moriasi et al., (2007).

Several studies have shown that when empirical equations are applied to basins other than the ones they were developed for they tend to lose their accuracy due to differences in physiography between the catchments including regional location, size, topography, land use, soils and climate (McCuen et al., 1984; Fang et al., 2008; Sharifi and Hosseini, 2011). To overcome these limitations, a correction factor is applied to the empirical equations to correct for any biases in their solution when the equations are applied to different geographic regions other than those they were originally developed for. The bias is minimized by correcting the slope of the regression line between the referenced and predicted values to equal 1 . Correction factors were applied to all of the equations with the exception of the NRCS velocity method to minimize the bias between the predicted values and the reference values for $T_{c}$. These correction factors are based on the inverse slope of the regression line between the predicted and referenced values; Table 3 lists the correction factors for each of the equations.

Table 3. The calibration factor for the models

\begin{tabular}{rc}
\hline \multicolumn{1}{c}{ Model } & Calibration Factor \\
\hline Williams (1922) & 0.642 \\
Kirpich (1940) & 0.389 \\
Chow (1962) & 5.613 \\
Kennedy and Watt (1967) & 4.155 \\
Watt and Chow (1985) & 2.918 \\
NRCS Velocity Method (1986) & Not Applicable \\
Haktanir and Sezen (1990) & 1.620 \\
Arizona DOT (1993) & 4.785 \\
Sharifi and Razaz (2014) & 1.130 \\
\hline
\end{tabular}

In addition, to the parametric analysis above, a quantitative assessment of the uncertainties in the prediction of $T_{c}$ was undertaken using the available empirical equations, regional equation, GEP equation and velocity method. The uncertainty analysis was applied to the complete dataset of 9 catchment measurements. The comparison is a fair indication of the predictive ability of the various equations. To minimize any bias in applying the various equations to this data set, a correction factor equivalent to the inverse slope of the regression line between the referenced and predicted values of $T_{c}$ was applied to the equations.

There has been no quantitative assessment of the effect of the stochastic character of the physical parameters of a catchment and their impact on the time of concentration. Therefore, a stochastic model was developed utilizing the regression equations for finding the approximate distribution of solution outcomes using Monte Carlo Simulation. Monte Carlo simulation is a relatively simple method to apply when assessing the uncertainty of an equation (Vose, 1996). In the present study, the uncertainty in $T_{c}$ is considered due to the uncertainty in the equation's input parameters, $A, L, L_{c}, S_{c}, S_{w}$, and $S T$. In addition to those parameters listed, Manning's " $n$ " value and the drainage density $(D D)$ are also included in the analysis. The input parameters are uncorrelated and are, therefore, considered to be independent variables, as such, random sampling can be applied without affecting the tails of the output distribution (Burmaster and Anderson, 1994).

Furthermore, a sensitivity analysis was employed in order to identify which variables have the most influence on the time of concentration. To investigate sensitivity, the variables in the equations for $T_{c}$ were perturbed by adding $10 \%$. The marginal sensitivity coefficient is determined as (Atieh et al., 2015a, b; Trenouth and Gharabaghi, 2015; Sattar and Gharabaghi, 2015):

$$
S_{c}^{*}=\frac{\Delta \theta}{\Delta T *}
$$

Where $S_{c}$ is the marginal sensitivity coefficient, $\Delta \theta$ is the change in the calculated objective function and $\Delta T^{*}$ is 
the change in the time constant parameter. Normalizing the parameters indicates the percent change in the objective function for a $1 \%$ change in each individual parameter. The marginal sensitivity coefficients were normalized to establish a basis for comparison using equation 2 .

$$
S_{n}=S_{c}^{*} \frac{T *}{\theta}
$$

Where $S_{n}$ is the normalized sensitivity coefficient, $T^{*}$ is the expected value of the perturbed time constant parameter, and $\theta$ is the expected solution.

\section{Results and Discussions}

The methodology for obtaining the reference $T_{c}$ values using the procedure outlined in section 3.1 was applied to 9 catchments of the Credit River watershed. The equations listed in Table 1 were used to predict the time of concentration for the 9 catchments along the Credit River; the values were compared against the reference $T_{c}$ values. The reference $T_{c}$ values for the nine gauging stations along the Credit River were compared against the values for $T_{c}$ from the "Travel Time Model for the Credit River," (Environmental Water Resources Group Ltd., 2007). The ratio between the reference $T_{c}$ values and the calculated values using the CVC's Travel Time Model was determined to be 1:1. Using a scatter plot, the results are illustrated in Figure 3. 


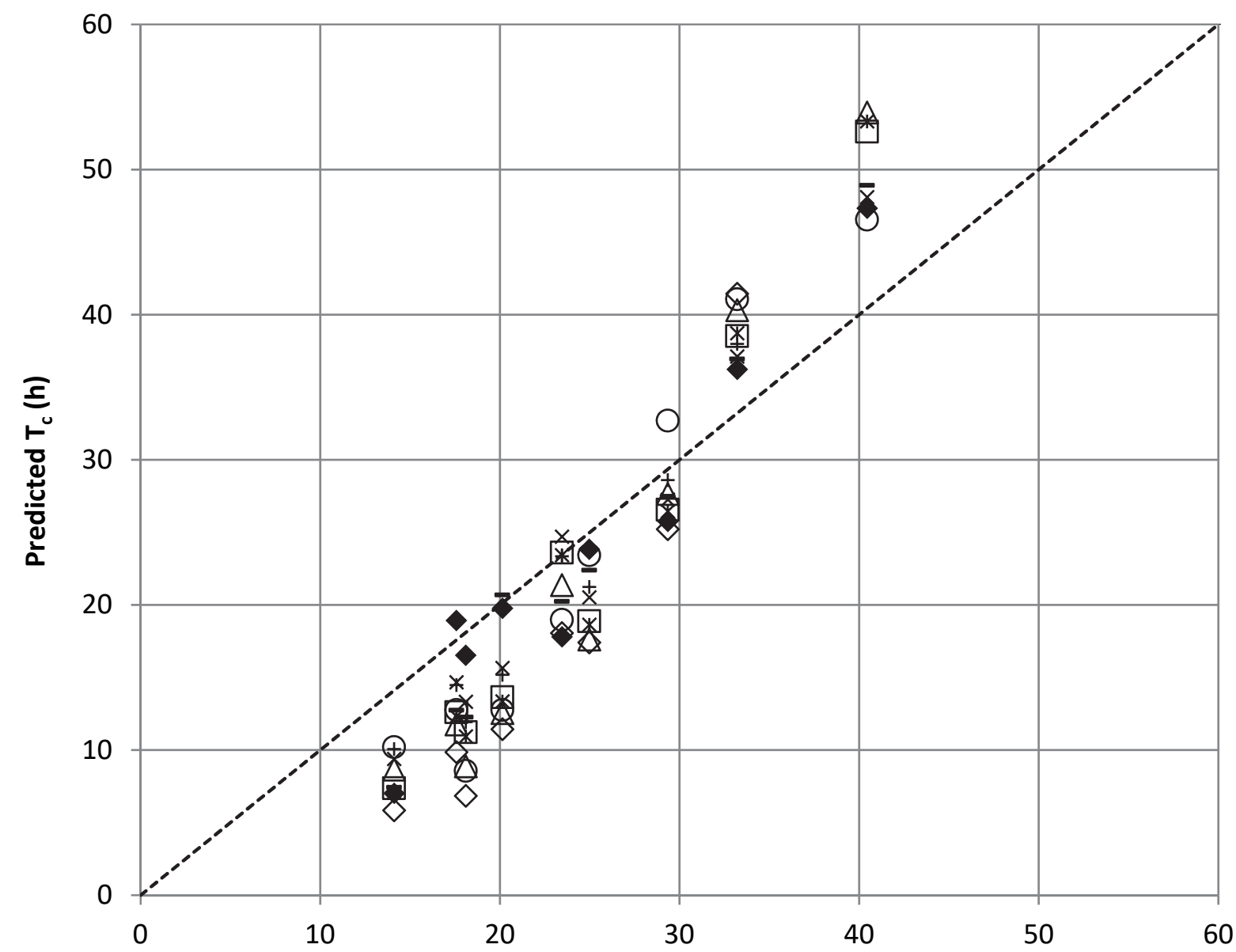

Reference $T_{c}(h)$

$\diamond$ Williams (1922)

$\times$ Chow (1962)

$\triangle$ Haktanir and Sezen (1990)

O Sharifi and Razaz (2014)

- NRCS Velocity Method (1986) $\square$ Kirpich (1940)

* Watt and Chow (1985)

+ Arizona DOT (1993)

- Kennedy and Watt (1967)

Figure 3. Scatter plot of reference time of concentration versus predicted time of concentration for the models

Figure 3 shows that all empirical equations tend to under predict Reference $T_{c}$ for the headwater basins of the Credit River and over predict $T_{c}$ for the downstream basins. Manning's roughness is not a constant value for all nine stations along the Credit River; upstream stations have higher roughness coefficients as the river is steeper and faster flowing river with shallower depths and larger bed material sizes while the lower Credit River is deeper and smoother sediments with lower roughness coefficients; the Manning's roughness change from upstream to downstream can explain why all empirical models that have overlooked the effect of Manning's roughness on Reference $T_{c}$ values for all 9 stations of the Credit tend to under predict $T_{c}$ values for headwater basins and over predict larger $T_{c}$ values for the downstream stations. However, the NRCS velocity method is the only method that takes Manning's $n$ variations into consideration and hence the higher accuracy of the model predictions.

In Southern Ontario, soil is often wet for roughly 10 months of the year, and a large percentage of the watershed 
drainage area actively contributes to surface runoff during storm events; therefore, the use of the correction factor also accounts for the antecedent moisture conditions of the Credit River basin compared to the basins where the original empirical equations were developed. According to Table 4, the NRCS velocity method is the most accurate and reliable approach for estimating the time of concentration of a catchment.

Table 4. Performance statistics of the models

\begin{tabular}{rcccccc}
\hline \multicolumn{1}{c}{ Model } & Rank & MAE & RMSE & MAPE (\%) & $\mathbf{R}^{2}$ & SE \\
\hline NRCS Velocity Method (1986) & 1 & 3.4 & 4.2 & 11 & 0.888 & 8.2 \\
Arizona DOT (1993) & 2 & 3.8 & 4.4 & 12 & 0.978 & 11 \\
Chow (1962) & 3 & 4.0 & 4.4 & 13 & 0.976 & 11 \\
Kennedy and Watt (1967) & 4 & 4.2 & 4.8 & 13 & 0.939 & 12 \\
Kirpich (1940) & 5 & 5.7 & 6.5 & 18 & 0.985 & 16 \\
Sharifi and Razaz (2014) & 6 & 5.4 & 5.9 & 17 & 0.927 & 14 \\
Watt and Chow (1985) & 7 & 6.0 & 6.8 & 19 & 0.986 & 17 \\
Haktanir-Sezen (1990) & 8 & 6.6 & 7.5 & 21 & 0.997 & 19 \\
Williams (1922) & 9 & 9.0 & 9.9 & 28 & 0.995 & 25 \\
\hline
\end{tabular}

Table 5 summarizes the results of the uncertainty analysis and shows the mean prediction errors of the various equations, the width of the uncertainty band and the $95 \%$ prediction interval error. The mean prediction error for empirical equations varied between 1.186 and $2.795 \mathrm{~h}$. The mean prediction error for the NRCS velocity method was $0.02 \mathrm{~h}$.

Table 5. Prediction error and uncertainty bands of the models

\begin{tabular}{|c|c|c|c|c|c|c|}
\hline Model & $\begin{array}{c}\text { Mean } \\
\text { Prediction } \\
\text { Error } \\
\text { (h) }\end{array}$ & $\begin{array}{l}\text { The width } \\
\text { of } \\
\text { Uncertaint } \\
\text { y Band } \\
\text { (h) }\end{array}$ & $\begin{array}{l}\text { 95\% Prediction } \\
\text { Error Interval } \\
\text { (h) }\end{array}$ & $\begin{array}{c}\text { Media } \\
\text { n (h) }\end{array}$ & $\begin{array}{c}\text { MA } \\
\text { D (h) }\end{array}$ & $\begin{array}{c}\text { Uncertainty } \\
\%\end{array}$ \\
\hline Williams (1922) & 2.795 & \pm 6.604 & +9.399 to -3.810 & 7.56 & 4.00 & 53 \\
\hline Kirpich (1940) & 1.816 & \pm 4.330 & +6.146 to -2.514 & 4.80 & 2.03 & 42 \\
\hline Chow (1962) & 1.186 & \pm 2.928 & +4.114 to -1.741 & 3.70 & 1.26 & 34 \\
\hline Kennedy and Watt (1967) & 1.601 & \pm 3.959 & +5.559 to -2.358 & 4.60 & 2.78 & 60 \\
\hline Watt and Chow (1985) & 1.909 & \pm 4.542 & +6.450 to -2.633 & 6.47 & 2.81 & 43 \\
\hline $\begin{array}{r}\text { NRCS Velocity Method } \\
\text { (1986) }\end{array}$ & 0.020 & \pm 1.221 & +1.242 to -1.201 & 12.4 & 4.95 & 40 \\
\hline Haktanir and Sezen (1990) & 2.069 & \pm 4.960 & +7.029 to -2.892 & 11.4 & 6.90 & 60 \\
\hline Arizona DOT (1993) & 1.233 & \pm 2.929 & +4.162 to -1.696 & 4.31 & 1.71 & 40 \\
\hline Sharifi and Razaz (2014) & 1.353 & \pm 3.198 & +4.552 to -1.845 & 17.8 & 10.4 & 58 \\
\hline
\end{tabular}

The uncertainty bands for the empirical equations ranged from \pm 1.74 to $\pm 6.60 \mathrm{~h}$. The uncertainty band for the NRCS velocity method was $\pm 1.22 \mathrm{~h}$, smaller than all the other methods. Similarly, the lowest $95 \%$ confidence prediction error interval was observed for the NRCS velocity method ranging from -1.20 to $+1.24 \mathrm{~h}$. In general, the NRCS velocity method had the highest performance with respect to prediction uncertainty band and $95 \%$ prediction interval.

Monte Carlo simulation was applied to the current study to determine the uncertainty in $T_{c}$ by each of the different 
methods due to uncertainty in the equations' input parameters, $A, L_{c}, L, L_{c a}, S_{c}, S_{w}, S T$, and $D D$. Distribution fitting was used to determine the probability distribution function (PDF) of various input parameters utilizing the complete set of measure data (all 9 catchments). Various distributions were tested, and the optimum distribution was chosen based on the ranking in fitting tests such as Kolmogorov-Smirnov, Anderson Darling and Chi Squared (Vose, 1996). Therefore, the variation in $A, L_{c}, L, L_{c a}, S_{c}, S_{w}, S T$, and $D D$ was modelled using a lognormal distribution with $($ mean $(\operatorname{Ln} x)=265.5,33.84,32.15,0.005,0.033,1.24$ and 0.22, $\operatorname{standard~deviation}(\operatorname{Ln} x)=293.5$, $27.82,27.68,0.002,0.011,0.16$ and 0.13 respectively).

For each Monte Carlo simulation run, the empirical equations, regional equation and NRCS velocity method for $T_{c}$ were used to obtain a single outcome. Therefore, 250,000 outcomes were calculated for $T_{c}$. The mean absolute deviation (MAD) is calculated around the median of the output distribution as;

$$
M A D=\frac{1}{250000} \sum_{i=1}^{250000}\left|P_{i}-\operatorname{Median}(P)\right|
$$

Once the MAD is calculated, the uncertainty of the equation output can be given as (Walker, 1931);

$$
\text { Uncertainty } \%=\frac{100 \times M A D}{\text { Median }(P)}
$$

Results of the uncertainty analysis for $T_{c}$ using the previous empirical models, regional equation and velocity method are presented in Table 5. The analysis for uncertainty for $T_{c}$ resulted in a MAD of 2.7, 2.8, 10.4 and 4.9 which are $48 \%, 60 \%, 58 \%$ and $40 \%$ of the median value for the empirical equations, regional equation, and velocity method.

Table 6 illustrates the sensitivity and effect of the input parameters on the time concentration for the models. It can be observed that the main channel slope $\left(S_{c}\right)$ and the main channel length $\left(L_{c}\right)$ scored the highest for $T_{c}$ in normalized sensitivity coefficients, for the empirical equations. The parameters $S_{c}$ and $L_{c}$ are the most common parameters used in empirical relationships to estimate the time of concentration Williams (1922), Kirpich (1940), Chow (1962), Williams (1968), Watt and Chow (1985) and Hakatenir and Sezen (1990). For the regional equation, the storage parameter $S T$ scored the lowest indicating that its effect is negligible in determining the time of concentration. Furthermore, the sensitivity analysis confirms the importance of the main channel slope parameter and the main channel length in estimating the time of concentration for a catchment regardless of the methodology used.

\begin{tabular}{|c|c|c|c|c|c|c|c|c|}
\hline Model & $\mathbf{L}_{\mathbf{c}}$ & $\mathbf{A}$ & $\mathbf{S}_{\mathbf{c}}$ & DD & ST & $\mathbf{L}$ & $\mathbf{S}_{\mathbf{w}}$ & $\mathbf{n}$ \\
\hline Williams (1922) & 1.100 & -10.44 & -5.196 & -- & -- & -- & -- & -- \\
\hline Kirpich (1940) & 1.413 & -- & -2.676 & -- & -- & -- & -- & -- \\
\hline Chow (1962) & 1.690 & -- & -3.229 & -- & -- & -- & -- & -- \\
\hline Kennedy and Watt (1967) & 1.450 & -- & -2.748 & -- & 0.858 & -- & -- & -- \\
\hline Watt and Chow (1985) & 1.379 & -- & -2.607 & -- & -- & -- & -- & -- \\
\hline NRCS Velocity Method (1986) & 0.334 & -6.635 & -6.635 & -- & -- & -- & -- & 2.261 \\
\hline Haktanir and Sezen (1990) & 1.298 & -- & -- & -- & -- & -- & -- & -- \\
\hline Arizona DOT (1993) & -- & -- & -- & -- & -- & 1.790 & -3.151 & -- \\
\hline Sharifi and Razaz (2014) & -- & 2.164 & -- & 64.58 & -- & -- & -- & -- \\
\hline
\end{tabular}

Table 6. Normalized sensitivity coefficients for the model's parameters

\section{Conclusions}

Prediction of flood flow hydrographs in ungauged river catchments is one of the most uncertain modelling tasks in hydrology due to large errors in the estimation of catchment response time parameters using existing empirical equations. The time of concentration $\left(T_{c}\right)$ is a key catchment response time parameter needed for predicting the peak discharge rate and timing of the flood event. However, a large number of definitions and empirical equations exist for estimating $T_{c}$ using the catchments' physical characteristics. The main objective of this study is to present "Reference $T_{c}$ " as a new unifying definition along with a practical procedure for its estimation using readily 
available basin catchment characteristic parameters to standardize this key parameter for practitioners. Nine different empirical models were tested on nine catchments of the Credit River watershed, Ontario, Canada to determine which method would provide the most accurate estimation of the reference time of concentration.

All empirical equations under predicted Reference $T_{c}$ for the headwater basins of the Credit River and over predicted Tc for the downstream basins. Manning's roughness is not a constant value for all nine stations along the Credit River; upstream stations have higher roughness coefficients as the river is steeper and faster flowing river with shallower depths and larger bed material sizes while the lower Credit River is deeper flows and smoother fine sediments with much lower roughness coefficients; the significant change in Manning's roughness coefficient from upstream to downstream basins can explain why all empirical models that have overlooked the effect of Manning's roughness on Reference $T_{c}$ values for the 9 stations of the Credit River tend to under predict $T_{c}$ values for the headwater basins and over predict $T_{c}$ for the downstream stations. However, the NRCS velocity method is the only method that takes Manning's roughness coefficient into consideration and hence the higher accuracy of the model predictions.

The sensitivity analysis confirmed the importance of the main channel slope parameter, channel roughness and the main channel length in estimating $T_{c}$ and regardless, which estimation method one selects, these parameters should be determined first. However, many basins have little to no hydrometric monitoring, and for these ungauged basins, one needs to rely on readily available catchment characteristic parameters to predict reference $T_{c}$. Therefore, in such cases, the NRCS velocity method can be used to determine the reference $T_{c}$ values for ungauged catchments following the procedures outlined in this study.

\section{Acknowledgments}

The authors would like to thank Natural Sciences and Engineering Research Council of Canada, Credit Valley Conservation Authority, Water Survey of Canada and the Ontario Ministry of Natural Resources for providing the necessary financial support, hydrometric and spatial data and another watershed characteristic information to undertake this study.

\section{References}

Annable, W. K. (1994). Database of Morphologic Characteristics of Watercourses in Southern Ontario. Ministry of Natural Resources and Forestry (MNRF), Peterborough, ON.

Arizona, Department of Transportation (ADOT). (1993) Highway drainage design manual hydrology, Phoenix.

Aron, G., \& Egborge, C. E. (1973) A practical feasibility study of flood peak abatement in urban areas. Report to the U.S. Army Corps of Engineers, Sacramento District, Sacramento, California.

Atieh, M., Gharabaghi, B., \& Rudra, R. (2015b). Entropy-Based Neural Networks Model for Flow Duration Curves at Ungauged Sites. Journal of Hydrology, 529(3), 1007-1020.

Atieh, M., Mehltretter, S., Gharabaghi, B., \& Rudra, R. (2015a). Integrated Neural Networks Model for Prediction of Sediment Rating Curve Parameters for Ungauged Basins. Journal of Hydrology, 531(3), 1095-1107.

Atieh, M., Taylor, G., Sattar, A. M., \& Gharabaghi, B. (2017). Prediction of flow duration curves for ungauged basins. Journal of hydrology, 545, 383-394.

Ayalew, T. B., Krajewski, W. F., \& Mantilla, R. (2015). Analyzing the effects of excess rainfall properties on the scaling structure of peak discharges: Insights from a mesoscale river basin. Water Resources Research. 51(6), 3900-3921.

Bell, F. C., \& Kar, S. O. (1969). Characteristic response times in design flood estimation. Journal of Hydrology, 8 , 173-196.

Ben-Zvi, A. (2012). Discussion of "Detention storage over 2D laboratory watersheds at concentration time". Journal of Hydrologic Engineering, 17(9), 1053-1057.

Bondelid, T. R., McCuen, R. H., \& Jackson, T. J. (1982). Sensitivity of SCS models to curve number variation. Water Resources Bulletin, 20(2), 337-349.

Chow, V. T. (1962). Hydrologic determination of waterway areas for the design of drainage structures in small drainage basins. University of Illinois Engineering Experiment Station Bulletin No. 462, Urbana, IL, p. 104.

Chow, V. T., Maidment, D. R., \& Mays, L. W. (1988). Applied Hydrology, McGraw-Hill, New York.

Clark, C. O. (1945). Storage, and the unit hydrograph. Transcripts American Society of Civil Engineers, 110, 14191446. 
Couture, R. (1978). Caractéristiques des crues estivales observées aux stations hydrométriques. Ministère des Richesses naturelles, Québec, P.Q., p. 46.

Disley, T., Gharabaghi, B., Mahboubi, A. A., \& McBean, E. A. (2015). Predictive equation for longitudinal dispersion coefficient. Hydrological processes, 29(2), 161-172.

Environmental Water Resources Group Ltd. (2007). Travel time model for the Credit River, Credit Valley Conservation, Mississauga, ON.

Fang, X., Cleveland, T., Garcia, C. A., Thomson, D., \& Malla, R. (2005). Literature review on timing parameters for hydrographs. Project Number 0-4696/1, Texas Department of Transportation, Austin, Texas.

Fang, X., Thompson, D., Cleveland, T. G, Pradham, P., \& Malla, R. (2007). Variations of time of concentration estimates using NRCS velocity method. Journal of Irrigation Engineering, 133(4), 314-322.

Fang, X., Thompson, D., Cleveland, T. G., Pradham, P., \& Malla, R. (2008). Time of concentration estimated using watershed parameters by automated and manual methods. Journal of Irrigation and Drainage Engineering, $134,202-211$.

Garg, S. K. (2001). Irrigation engineering and hydraulic structures, Khanna Publishers, New Delhi, India.

Gazendam, E., Gharabaghi, B., Ackerman, J. D., \& Whiteley, H. (2016). Integrative neural networks models for stream assessment in restoration projects. Journal of Hydrology, 536, 339-350.

Goitom, G. T. (1989). Evaluation of $T_{c}$ methods in a small rural watershed. In: Channel Flow and Catchment Runoff (Proceedings International Conference for Centennial of Manning's Formula and Kuichling's Rational Formula, May 1989), 88-96.

Grimaldi, S., Petroselli, A., \& Romano, N. (2013b). Green-Ampt Curve-Number mixed procedure as an empirical tool for rainfall-runoff modelling in small and ungauged basins. Hydrological Processes, 27(8), 1253-1264.

Grimaldi, S., Petroselli, A., Arcangeletti, E., \& Nardi, F. (2013a) Flood mapping in ungauged basins using fully continuous hydrologic-hydraulic modeling. Journal of Hydrology, 487, 39-47.

Grimaldi, S., Petroselli, A., Nardi, F., \& Alonso, G. (2010) Flow time estimation with variable hillslope velocity in ungauged basins. Advances in Water Resources, 33(10), 1216-1223.

Gupta, H. V., Sorooshian, S., \& Yapo, P. O. (1999) Status of automatic calibration for hydrologic models: Comparison with multilevel expert calibration. Journal of Hydrologic Engineer, 4(2), 135-143.

Haktanir, T., \& Sezen, N. (1990) Suitability of two-parameter gamma and three-parameter beta distributions as synthetic unit hydrographs in Anatolia. Hydrologic Science Journal, 35(2), 167-184.

Henderson, F. M., \& Wooding, R. A. (1964) Overland flow and groundwater flow from a steady rainfall of finite duration. Journal of Geophysics Research, 69(8), 129-146.

Hoang, C. D. (1977). Estimation des débits journaliers de crue printoniére des rivières du Québec méridional. Ministére des Richesses naturelles, H.P.-40, Quebec, P.Q., p. 43.

Izzard, C. F. (1946). Hydraulics of runoff from developed surfaces. Proceedings 26th Annual Meetings of the Highway Research Board, National Research Council, Washington, D.C., 26, 129-146.

Kennedy, R. J., \& Watt, W. E. (1967). The relationship between lag time and the physical characteristics of drainage basins in southern Ontario. International Association of Scientific Hydrology, publication No. 85. pp. 867874.

Kibler, D. F., \& Aron, G. (1983). Evaluation of $T_{c}$ methods for urban watersheds. In: Frontiers of Hydraulic Engineering (Proceedings MIT ASCE Symposium, August 1993): 555-559.

Kirpich, Z. P. (1940) Time of concentration of small agricultural watersheds. Journal of Civil Engineering, 10(6), 362.

Li, M. H., \& Chibber, P. (2008). Overland flow time of concentration on very flat terrains. Transportation Research Record 2060, Transportation Research Board, Washington, DC, 133-140.

Liu, Y., Yang, W., Yu, Z., Lung, I., \& Gharabaghi, B. (2015). Estimating sediment yield from upland and channel erosion at a watershed scale using SWAT. Water resources management, 29(5), 1399-1412.

Loukas, A., \& Quick, M. C. (1996). Physically-based estimation of lag time for forested mountainous watersheds. Journal of Hydrological Sciences, 41(1), 1-19.

McCuen, R. H., Wong, S. L., \& Rawls, W. J. (1984). Estimating urban time of concentration. Journal Hydraulic 
Engineering, 110(7), 887-904.

Morgali, J. R., \& Linsley, R. K. (1965). Computer analysis of overland flow. Journal of Hydrology Division, 91(HY3), 81-100.

Moriasi, D. N., Arnold, J. G., Van Liew, M. W., Binger, R. L., Harmel, R. D., \& Veith, T. L. (2007). Model Evaluation Guidelines for Systematic Quantification of Accuracy of Watershed Simulations. Transactions of the American Society of Agricultural and Biological Engineers, 50(3), 885-900.

Nardi, F., Annis, A., \& Biscarini, C. (2015). On the impact of urbanization on flood hydrology of small ungauged basins: the case study of the Tiber river tributary network within the city of Rome. Journal of Flood Risk Management. https://doi.org/10.1111/jfr3.12186.

Nathan, R. J., \& McMahan, T. A. (1990). Evaluation of Automated Techniques for Baseflow and Recession Analysis. Water Resources Research, 26(7),1465-1473.

Natural Resource Conservation Service (NRCS). (1972). Hydrology. National Engineering Handbook, Section 4, U.S. Department of Agriculture, Washington, D.C.

Natural Resource Conservation Service (NRCS). (1986). Urban Hydrology for Small Watersheds. Technical Release 55, Washington, D.C.

Natural Resource Conservation Service (NRCS). (2012). Part 630 Hydrology Chapter 18: Selected Statistical Methods. National Engineering Handbook, Section 4, U.S. Department of Agriculture, Washington, D.C.

Perdikaris, J., Gharabaghi, B., \& Rudra, R. (2018). Evaluation of the Simplified Dynamic Wave, Diffusion Wave and the Full Dynamic Wave Flood Routing Models. Earth Science Research, 7(2), 14.

Perdikaris, J. (2013). Guelph Flood Forecasting Model (GFLOOD): An innovative approach to estimating flows and waters levels in streams. Ph.D. Dissertation, School of Engineering University of Guelph.

Perdikaris, J., Gharabaghi, B., \& McBean, E. (2011). A Methodology for Undertaking Vulnerability Assessments of Flood Susceptible Communities. International Journal of Safety and Security Engineering, 1(2), 126-146, https://doi.org/10.2495/SAFE-V1-N2-126-146.

Petroselli, A., \& Grimaldi, S. (2015). Design hydrograph estimation in small and fully ungauged basins: a preliminary assessment of the EBA4SUB framework. Journal of Flood Risk Management. https://doi.org/10.1111/jfr3.12193.

Sattar, A. M., \& Gharabaghi, B. (2015). Gene expression models for prediction of longitudinal dispersion coefficient in streams. Journal of Hydrology, 524, 587-596.

Seyam, M., \& Othman, F. (2014). The Influence of Accurate Lag Time Estimation on the Performance of Stream Flow Data-driven Based Models. Water Resources Management, 28(9), 2583-2597.

Sharifi, S., \& Hosseini, M. (2011). Methodology for identifying the best equations for estimating the time of concentration of watersheds in a particular region. Journal of Irrigation Engineering, 137, 712-719.

Sharifi, S., \& Razaz, M. (2014). A New Methodology for Deriving Regional Time of Concentration Equations Using GIS and Genetic Programming. City University New York, Academic Works.

Singh, J., Knapp, V. M., \& Demissie, M. (2004). Hydrologic modeling of the Iroquois River watershed using HSPF and SWAT. ISWS CR 2004-08. Champaign, Ill.: Illinois State Water Survey.

Singh, V. P. (1988). Hydrologic Systems: Rainfall-runoff modeling, Vol. 1, Prentice-Hall Englewood Cliffs, New Jersey.

Trenouth, W., \& Gharabaghi, B. (2015). Event-Based Soil Loss Models for Construction Sites. Journal of Hydrology, 524, 780-788.

USDA, Soil Conservation Service. (1985). Hydrology, National Engineering Handbook section 4, (NEH-4).

Vose, D. (1996). Quantitative Risk Analysis: A Guide to Monte Carlo Simulation Modelling. John Wiley, New York, $\mathrm{p} 317$.

Watt, W. E., \& Chow, K. C. (1985). A general expression for basin lag time. Canadian Journal of Civil Engineering, $12,294-300$.

Williams, G. B. (1922). Flood discharges and the dimensions of spillways in India. Engineering (London), 134, 321.

Williams, J. R., \& Hann, R. W. (1973). HYMO: problem-oriented computer language for hydrologic modeling 
user's manual. ARS-S-9, Agricultural Research Service, U.S. Department of Agriculture, Riesel, Texas, 76 pp.

Williams, J. R. (1968). Runoff Hydrographs from Small Texas Black Lands Watersheds. US Department of Agriculture, ARS 41-143, October 1968.

Wong, T. S. W. (2005). Assessment of time of concentration formulas for overland flow. Journal Irrigation and Drainage Engineering, 131(4), 383-387.

Wong, T. S. W. (2009). Evolution of kinematic wave time of concentration formulas for overland flow. Journal of Hydrologic Engineering, 14(7), 739-744.

Wong, T. S. W., \& Chen, C. N. (1997) Time of concentration formula for sheet flow of varying flow regime. Journal of Hydrologic Engineering, 2(3), 136-139.

Wong, T. S. W. (1995). Time of Concentration Formulae for Planes with Upstream Inflow. Journal of Hydrological Sciences, 40(5), 663-666.

Wong, T. S. W. (1996) Time of Concentration and Peak Discharge Formulas for Planes in Series. Journal of Irrigation and Drainage Engineering, ASCE, 122(4), 256-258.

\section{Copyrights}

Copyright for this article is retained by the author(s), with first publication rights granted to the journal.

This is an open-access article distributed under the terms and conditions of the Creative Commons Attribution license (http://creativecommons.org/licenses/by/4.0/). 